\title{
Clinical Reflection: The experience of Nursing Students in the Obstetric Unit
}

\author{
Lilibeth Al-Kofahy ${ }^{*}$ and Linda James
}

School of Nursing, Sam Houston State University, 1905 University Ave, Huntsville, TX 77340, USA

\section{Abstract}

Background: The reflective journal, a tool in students' learning that helps student reflecting on and store their clinical learning in their memory. It also helps in better understanding of clinical practice as well as understanding of what they experienced and learned, provided the clinical instructors are not available for every student all the times. The outcome increases the confidence of the students and facilitates the ability of the instructor to customize clinical experiences for individual students based on their learning gaps.

Method: Reflective journals of 40 nursing students from fall and spring 2013-2014 assigned to their Obstetric $(\mathrm{OB})$ clinical placement were analyzed. Of them, 12 were interviewed face-to-face and were asking to relay their experiences in the postpartum units, labor and delivery, antepartum, and neonatal intensive care unit (NICU). Interviews were digitally recorded and transcribed verbatim. A qualitative phenomenological approach was used to explore the basic social process, which attempts to transcend student nurses' experience regarding clinical reflection as a continual process and move it from a description of what is happening to an understanding of the process by which it happens.

Findings: The findings of this study have the potential to contribute new knowledge concerning the process of experiential learning using reflection. Through reflection, nursing students in their obstetric clinical rotations demonstrated progress towards professional nursing status by developing confidence, and knowledge in nursing.

Conclusion: Reflective journals as an educational strategy for facilitating learning in the extent of practice setting, and level of reflection achieved. Maternal-child nursing student was the participant in the process of his/her own clinical experience in various areas in the OB clinical unit. Reflective journaling also facilitates the nursing students' learning and progress towards building confidence and knowledge, which are main components in providing quality of care.

\section{Introduction}

Nursing student's reflective journaling has become established as a significant part of deep nursing practice, and vital to the concept of learning from experience. Statements are made in the reflective practice literature of the capacity for reflective journaling to develop the writer's critical thinking and analytical abilities, which contribute to their development as professionals, enable creativity and unique connections to be made between different sets of information, and to contribute to new knowledge about issues. All of these are qualities to be anticipated in confident students. Therefore, this study considers the descriptions of reflective journaling and its use within qualitative research as a method in its own right, as a data source and as an analytical process references.

The aims of the current study were to analyze reflective journals written by nursing students while enrolled in the maternal-child nursing course at Sam Houston State University (SHSU) during fall, 2013 and spring, 2014 as well as to examine the use of reflective journals as an educational strategy for facilitating learning in the practice setting; and extent and level of reflection achieved.

The study was focused on the maternal and newborn experience of reflection within the Obstetric $(\mathrm{OB})$ unit accessed by nursing students, in the clinical unit. Through an interpretive and descriptive approach, the organizational and contextual impact upon teaching and learning interactions and the use of reflection therein has been explored. Data has been collected from written reflection and interviews of nursing student's experiences during clinical rotation in the $\mathrm{OB}$ unit

\section{Review of the Literature} units are scarce. E-mail: Ixa019@shsu.edu doi.org/10.15344/2394-4978/2017/243 and source are credited.

\section{Publication History:}

Received: April 25, 2017

Accepted: July 08, 2017

Published: July 10, 2017

\section{Keywords:}

Experience, Journal, Nursing students, Obstetrics, Reflection

The reflective journal, a tool in students' learning that helps student reflecting on and store their clinical learning in their memory. It also helps in better understanding of clinical practice as well as understanding of what they experienced and learned, provided the clinical instructors are not available for every student all the times. The outcome increases the confidence of the students and facilitates the ability of the instructor to customize clinical experiences for individual students based on their learning gaps.

Reflective journal writing has frequently been used in nursing and other health care fields as an educational approach to promote reflection and learning outcomes. Studies on evaluate its use as a teaching strategy for nursing students in the Obstetric and related

"Corresponding Author: Prof. Lilibeth Al-Kofahy, School of Nursing, Sam Houston State University,1905 University Ave, Huntsville, TX 77340, USA;

Citation: Al-Kofahy L, James L (2017) Clinical Reflection: The experience of Nursing Students in the Obstetric Unit. Int J Nurs Clin Pract 4: 243. doi: https://

Copyright: @ 2017 Ueno et al. This is an open-access article distributed under the terms of the Creative Commons Attribution License, which permits unrestricted use, distribution, and reproduction in any medium, provided the original author 
Reflective learning is of particular significance to the education of nursing students as it inspires them to integrate theory and practice and through reflective writing, turns every experience into a new prospective learning experience [1]. The nursing literature focuses the need to promote the concept of reflective practice to assist students in reflection of their experiences [2-6]. Many studies, demonstrate various approaches to the use reflective writing to teach nursing concepts. These approaches include the use of reflective diaries or journals $[5,7,8]$ and the use of reflection within group discussion. Most of the literature relating to these approaches however is anecdotal in nature. The requirement to develop increasingly self-aware or selfreflective in practice is strongly encouraged.

A number of challenges including the effects of market instabilities and government-led social and health care methods have influence health care with a goal of improving health outcomes for clients. There is an acknowledgement that constant change is now an ongoing feature of health care delivery. Nursing students are expected to be able to respond to changes in the nursing profession with flexibility. According to Williams et al. [9] major changes in attitudes and practices are required in order to work confidently and to maintain professional growth as professional nurses. The researchers [9] believed that the motivation to learn from reflective processes has the potential to enhance and educate the practical learning experience and can aid the nursing students in labeling and recognizing their thoughts, actions, and it is resulting impact in a given situation.

Within nursing there has presently been an evolving awareness of the way students learn. Nursing students' encounter situations within practice and need flexible ways of responding to and learning from these situations. It has been acknowledged in the literature that it is essential for practicum experiences in nursing education to be a central component of education for quality learning McCaugnerty, [10]; Mouniford and Rogers [11]. Without this emphasis on practicum it is unlikely that the skills required for proficient practice will be developed. It is therefore, essential that approaches that facilitate learning through practice be considered. The need for a tool, which experts can use to facilitate learning through practice, is vital. One such tool, which may support quality learning through practice, is reflection.

Two thousand, nine hundred and eight registered nurses (including part-time workers) participated in the study, all of whom were working at the 11 subject hospitals and all of whom had three or more years career experience.

According to Mezirow [12] critical reflection involves the scrutiny of previously held views or perceptions by reflecting back on prior learning in demand to assess the validity of these assumptions within a new situation. Schön [7] has argued that student nurse's must modify their clinical practice to becoming more reflective so that they may meet the essentials needs of their patients. He also mentions that the rules or theories need to maintain to guide nursing student's use and practice may be effective at times, given to each patient or as a unique situation. There are no pre-set solutions to real life problems. Nursing students need develop their worldview of nursing [7]. Therefore, the challenge for educators is to help individual learner's process everyday clinical situations in a competent manner to become independent student nurses while developing expert clinical judgment.

Reflection has been identified as an effective learning strategy that can assist nursing students to become independent with sound clinical judgment $[5,7,13,14]$. However, Schön [7] has argued that traditional nursing schools are not preparing students for confident in real life situations. He claims that the educational preparation of nursing professionals should be centered on enhancing the nursing student's ability to reflect since it can facilitate the integration of theory and practice [15]. A number of recent experimental studies by Clarke, James, and Kelly [5,16]; Wong et al.,[1] and Jasper [17] conclude that the nursing profession has embraced reflection as a teaching and learning method. Nursing student's reflection used as a teaching and learning tool to improve nursing practice through the advancement of their ability to contextualize knowledge with flexibility to meet patients' needs. This involves the student being able to think clearly, to reason and to use effective problem-solving approaches in the practical situations. Problem solving demands that the student nurse thinks critically about the knowledge needed in practice to provide quality care.

The difficulty of the nursing situation is assessed critically and intuitively and situational knowledge grounded in practical experience is accessed to solve context-bound situations. This is what is known as professional practice [18]. Also, the author mentions that clinical experiences are in continual learning with the context of the nursing situation by analyzing, reviewing, grasping, and interacting with it. There is further reviewing their intentions and refining their actions. He points out those nursing students have a depth of personal knowledge and insights that may not be demanded of other occupations [18]. Nursing actions are developed and may then practice when nursing experiences are examined through reflection. The nursing student becomes aware of the various components of an experience that helps them to integrate the knowledge, which forms the basis of professional practice.

The writing of a journal as a means of promoting reflection and learning in educational settings has been encouraged $[8,13,19$ 21]. There is an association between the skills required for journal writing and that for reflection. These skills include open-mindedness, motivation, self-awareness, ability to describe and observe, as well as critically analyze, problem solve, synthesize and evaluate [14]. As a result, some advocate for the development and use of a tool to support reflective writing to enhance the qualities and skills required for reflection. Reflective journal writing was also introduced into different courses where the researchers are employed, as a tool to promote reflection in learning and as a form of self-evaluation of students' learning. Students' comments on the evaluation of their usefulness have been variable. Some students are more easily able to perform reflective writing and demonstrate higher-level learning benefiting them more than those who find the process challenging.

The researchers have therefore become increasingly interested in the role of journal writing in promoting reflection and learning in nursing students. There is some evidence to suggest that journals can be used as an effective tool to promote reflection; however, there is scope for further evaluation of their role in relation to their effectiveness [1,22]. The current study was involved nursing students who were assigned in antepartum, postpartum, labor and delivery, and NICU unit and have used a reflective journal as a tool to promote reflection during a fifteen-week semester. While undertaking a number of the clinical assignments as part of these programs, the students benefit from a shared learning experience, as a number of assigned units, which are common to both pathways. The nursing students have variable years of experience and attend the clinical education setting one day each week in order to undertake their studies. 


\section{Definitions of Reflection}

The absence of a clear definition of reflection is apparent within the literature [12,19,23]. Schön [7] defines clinical reflection in terms of action, both as reflection-in-action, where a student 'reflects on his/her own experience during clinical practice by challenging and clarifying problems. Where-as, reflection-on-action occurs after the clinical experience where the student critically examines what has been done and learns about what work and what did not work. This reflection-on-action is similar to what Emden [4] believes to be the kind of action that allows for effective problem solving and learning taking place. Dewey further describes reflection as a learning loop frequently feeding back and forth between the experience and relationships being gathered. Foster \& Greenwood [6] described the experiential learning sequence, which begins with a concrete experience followed by observation and reflection. The reflective observations are translated into a theory for use in future experience. In addition, learning is both an experiential and a reflective process, in which observations and reflections are interpreted and integrated into cognitive processes to become new, or expanded as wholes [6].

In addition, Schön [7] defines clinical reflection in terms of action, both as reflection-in-action, where a student 'reflects on his/her own experience were developing and challenging clarifications when they encounter problems in clinical practice, and reflection-on-action, where a student looks back at what has been done and, through reflecting on it learns lessons from what did or did not work. This reflection-on-action is similar to what Foster and Greenwood [6] believes to be the kind of action that allows effective problem solving to take place and he also suggests that it improves the effectiveness of learning. Foster and Greenwood [6] also describes it as a learning loop, frequently feeding back and forth between the experience and relationships being gathered. Cameron and Mitchell [8] described the experiential learning sequence, which begins with a concrete experience followed by observation and reflection. The reflective observations are translated into a theory for use in future experience. In addition, learning is both an experiential and a reflective process, in which observations and reflections are interpreted and integrated into cognitive processes to become new, or expanded as wholes [20].

Boud et al. [13] defined reflection as a generic term for those intellectual and affective activities in which individuals engage to explore their experiences on order to lead to new understanding and appreciations. [13]. However, Leino-Kilpi [15] suggest that reflective learning is the process of internally examining and exploring an issue of concern, triggered by and experience, which creates and clarifies meaning in terms of self, and which results in a changed perspective. Also, Mezirow[12] defined reflective thought as active, persistent and careful consideration of any belief or supposed form of knowledge in the light of the grounds that support it and the further evidence by which the reliability and worth of a belief can be established so as to justify its acceptance [12].

It was clear from the latter two subsequent definitions that the authors understand the processes of reflection as involving the nature, and the outcome of reflection as a changed theoretical perspective. A number of other author's definitions were less clear although most acknowledge an active element to the reflective process $[4,17]$. These authors also adopt that reflective practice founded in action to bring about deliverance and authorization primarily for the individual, but also influence the practice of others, through nurse-patient interactions, clinical decision-making and ethical debate. However, other authors [12,14] definition does not include the individual and while they states that reflective practice is a potential learning situation that does not indicate that it necessarily results in a changed conceptual perspective. What all these authors have in common, however, is that they discuss the processes of reflection.

\section{Methods}

Reflective journals of 40 nursing students from fall and spring 2013-2014 assigned to their Obstetric (OB) clinical placement were analyzed. Of them, 12 were interviewed face-to-face and were asking to relay their experiences in the postpartum units, labor and delivery, antepartum, and neonatal intensive care unit (NICU). Interviews were digitally recorded and transcribed verbatim [24]. The following questions were addressed: (1) Discuss the process you used to develop your reflective writing? (2) What were the benefits if any to you in writing the reflective journal during your maternal-child clinical experience? (3) Could you talk about development of your ability and performance in maternal-child nursing as you progressed through the semester? (4) Do you think that reflective journaling had any impact on your experience?

Reflective journals and interviews were analyzed using qualitative content analysis. Qualitative content analysis is an interpretive process, focusing on subject and context, and dealing with differences and similarities between, and within, parts of the text. It is a systematic method of analyzing written or verbal communication [25], which is useful in the analyses of a person's experiences, reflections, and attitudes.

\section{Data analysis}

A qualitative phenomenological approach [26] was used to explore the basic social process, which attempts to transcend nursing students' experience regarding clinical reflection as a continual process and move it from a description of what is happening to an understanding of the process by which it happens. The authors reviewed significant statements that explicated from 40 reflective journals and the nursing students' interview transcripts were then reread several times to obtain a sense of their respective meanings. Ways related to the participants' experiences of reflection through practice were then extracted and brought together in to a single text. From this, meaning units, each comprising several words, sentences, or paragraphs related to each other through their statements were condensed and labeled with numbers. The numbers and meaning units were interpreted in context, matched for differences and similarities, and abstracted to build tentative subthemes comprising recurrent threads of meaning [27].

\section{Results}

The study findings have the potential to contribute new knowledge concerning the process of experiential learning using reflection. Through reflection, nursing students in their obstetric clinical rotations demonstrated progress towards professional nursing status by developing confidence, and knowledge in nursing.

The reflection is continuously to enable the nursing students to tell their stories of what experience they have had in the clinical practice [28]. Nursing students tell their stories intensely because these experiences develop as significant for them in confident and knowledgeable approach. Nursing students have recognize, challenge, and determine the conflicts between what the actual practice achieved 
with the intent to achieve more desirable and effective work [28]. In order to develop clinical experience, nursing students must reflect on what they do and what they would want to do better.

According to participants' experience always provides an opportunity to make a link between theory and practice. One student commented: "I think the best way to learn it is to practice it".

The findings showed that experience was not limited to direct involvement in an activity and may embrace other routes such as observing and listening to people who have had more or different experience. One student said: "I like to listen to more experienced nurses' clinical stories. They gave me many useful indications". The importance of indirect experiences through observation and demonstration in clinical learning unit has been emphasized in the literature. The findings indicated that the handover (the report at the change of shifts) is a powerful means of transferring knowledge that could increase the nursing student's confidence it is considered appropriately [28,29,]. One student stated: "being present at handovers . . especially in morning handovers is very useful. When the nurse in charge is reporting the previous night's situations, I learn a lot about how I should act if those happen to me sometimes later".

As time passes and the anticipated work becomes familiar, the nursing student becomes eager to be engaged in performing the work directly, a situation that is called direct experience. At this time, the nursing student often begins this type of experience conventionally by doing a part of the work. A student commented: "you should be patient, do it step by step, and you will be a confident nursing student". The nurse obeys the rules or procedure strictly and is apparently dependent on other skilled professional nurses in doing the anticipated work. Certainly, in this experience the nursing student needs a clinical instructor/preceptor who provides appropriate help and, more importantly, support. For example, one student said: "when you are doing a patient care for the first time, you actually need a person who says 'this is what you need to do... this is the way to perform". At this point, nursing students highly value expert feedback because it can increase the student's self-esteem and ultimately improve performance. If there is no appropriate feedback on progress, the student may feel unsure of how others perceive his or her ability.

The nursing student needs experience to confirm his or her ability to work and needs relevant feedback and support to progress to the following level. Consistent practicing is important, and any delay in the association of experience may lead to loss of even existing confidence. One student stated: "until you've got experience on realities. On clinical unit, you can't start understanding how things go together". The nursing student experience of the process becomes merged with the level of confidence development. In this experience, the student tries to gain complete mastery of the procedure and improves the performance through frequent practice and challenging new, interesting situations. Therefore, practicing and challenging different situations provide the student with good opportunities to employ what has been cited in literature as reflection for improving performance [30]. As one student stated: "sometimes I think to myself 'what was the best result to that clinical situation"? The nursing student enjoys practicing and facing challenges, especially when these are accompanied by learning success. The impact of these successes in enhancing the student's confidence has been highlighted in the literature [29]. And also notices others' feedback wisely but mostly values self-evaluation of the work. A student stated: "at first I was eager to know my instructor/ preceptor's feedback about my tasks, but now I know exactly what my weaknesses and strengths are myself?.
Clinical setting was also indication of one of the important factors that could strongly affect, positively or negatively in the process of confidence development in the nursing students. Clinical setting, both physical and emotional, was recognized in this study as being important to the development of nursing students' confidence. Factors such as rapid change due to the introduction of new technology or working in a highly specialized unit with a variety of equipment (e.g., operating room-C/section) require student to do or/and perform their best to become confident. However, working in obstetric units, in teaching hospitals where most hands-on jobs are performed by registered nurses, and license vocational nurses were seen as providing less chance for confidence development for nursing students. Many students have similar statements were working in a labor and delivery and postpartum unit stated: "I have no authority, I have to call assigned registered nurse for everything even doing a ambulating of a post surgery C-section patient".

However, those participants who assigned in the Obstetric antepartum unit believed these settings were more appropriate for confidence and knowledge development because there were no instructors with them, and no enough registered nurses in these settings; so they had to learn whatever a License Vocational Nurses (LVNs) must do. In addition, the emphasis on effectiveness in these settings, sometimes nursing student assigned to work in different areas in a rotating manner, enabling them to be familiar with many different procedures in different units. One student said: “. . . in this settings we have to rotate in different units and this made us familiar with different procedures".

Units' setting as communicated by participants could have an impact on their nursing confidence development. Working in different settings (clinical rotation) where there was mutual respect, support, and trust from preceptors who valued, motivated and provided supportive relationships could fulfill nursing students' self-actualization needs. Furthermore, keeping of nursing improvement effective, providing a natural and pleasant working environment, and subsequently inspire nursing students to a greater readiness for learning and taking roles and responsibilities are significantly contributed in the development of students confidence. Usually, this setting could be best found in university-affiliated hospitals units in particular. In such settings, there were numerous learning opportunities combined with constructive scientific discussion provided by attending physicians and students of different disciplines. One student who was assigned in the NICU stated: "here in contrast to Labor and Delivery or postpartum unit, I am comfortable everything is nice here, I loved it". We work alongside pleasant nurses from different disciplines and ask each other everything we don't know".

The value of personal characteristics such as curiosity, and readiness to know more about anything relating to working in the clinical area, willingness to ask questions or to get help, and involvement in any activities that could increase professional abilities were seen as important personal characteristics that influence confidence development in nursing students. Many students stated, "if I don't know something, I will ask from everyone who could help me doctors, co-students or even auxiliary nurses. I think that's mystrength." Another student stated: "I haven't turned down any work that has been offered to me so far. I have accepted it all. I've realized it will all be a learning experience". Some student nurses stated: "I ask for help when I need it but at the same time, you know, I can use my own initiative. I can get on with things on my own. I don't need a great deal of guidance." 
The importance of the above-mentioned factors in confidence development has been cited in the literature. Jonsen et al., [29] acknowledged the value of having confidence and commitment, which ultimately affect the learner's motivation to learn in the clinical practice, and Ganzer and Zauderer [31] suggested "lifelong learning requires nurses to depend on themselves to learn what is needed to enhance their confidence and knowledge after graduation" (p. 246).

Data revealed that the nursing students in the current study prioritized patients' benefits over their own self-interest, which could be interpreted as their commitment to the clinical practice. This in turn increased their eagerness to improve their clinical confidence and knowledge. Two students said, "I think the patient is more important than my self-importance". According to Jonsen et al. [29], commitment to the importance of the clinical setting is a primary factor that affects the extent to which professionals are positive in taking advantage of available learning opportunities.

The findings of this current study suggest that nursing student's confidence and knowledge develop during a gradual process and requires patience and deliberation. The constant interaction process that emerged from this study indicates that nursing students need to take an active role in their own confidence development if the efforts they employ in this way are to be successful. Meanwhile, the study has generated a substantive theory that can provide useful insights into the reality of the confidence development process within the nursing profession. This theory, if confirmed in further testing, could enable preceptors and educators to have a new perspective on this important phenomenon. This could enable them to create new plans for the development of clinical confidence and knowledge for nursing students that eventually could result in better patient care and improved standards of nursing.

\section{Discussion}

The important significance of findings in this current study are the level where confidence and knowledge increase into place, which appears in reflection, filled with challenges that appeal to the nursing students. These include sensitivity towards their development of confidence and their needs for interconnecting theory and practice to build their knowledge. Confidence and knowledge meet in a productive collaboration in of positive response that offers appealing challenges. The nursing student then has the courage to dare to progress in his/her caring and learning process. In knowledge, it is possible to face up to exhilarating challenges. Appealing challenges, such as taking more responsibility and gaining greater independence, help to integrate students' confidence and knowledge. A new understanding and confirmation of thoughts and actions are revealed in an experience containing reaction, conversation and reflection. Statements, responses, both verbatim and through body language, provide guidance about confidence and knowledge. The desire to develop in a new role as a nursing student in the Obstetric unit encourages them to make progress and accept the challenges. The drive to find one's own personal style is supported in an experience where this desire is understood, where there is opportunity for developing independence and where the possibility for providing care supports the learning. A clinical reflection can thus be seen as one that is flexible, from providing a secure foundation to providing the opportunity for increasing the nursing student's responsibility and independence on the way to finding a new role and personal style. The following themes confidence and knowledge find a new role; further explicate the meaning of the phenomenon.

\section{Conclusion}

Reflective journal is an educational strategy for facilitating learning in the extent of practice setting, and level of reflection achieved. Maternal-child nursing student was the participant in the process of his/her own clinical experience in various areas in the $\mathrm{OB}$ clinical unit. Reflective journaling also facilitates the nursing students' learning and progress towards building confidence and knowledge, which are main components in providing quality of care.

\section{Competing Interests}

The authors declare that they have no competing interests.

\section{References}

1. Wong FKY, Kember D, Chung LYF, Yan L (1995) Assessing the levels of student reflection from reflective journals. Journal of Advanced Nursing 22: 48-57.

2. Clarke $M$ (1986) Action and reflection: practice and theory in nursing. Journal of Advanced Nursing 11: 11.

3. Lister $P$ (1989) Experiential learning and the benefits of journal work. Senior Nurse 9: 20-21.

4. Emden C (1991) Becoming a reflective practitioner. In: Towards a Discipline of Nursing. Longman. Singapore 334-355

5. Durgahee $T$ (1996) Promoting reflection in post-graduate nursing: a theoretical model. Nurse Education Today 16: 419-426.

6. Foster J, Greenwood J (1998) Reflection a challenging innovation for nurses. Contemporary Nurse 41: 165-172.

7. Schön D (1987) Educating the Reflective Practitioner. San Francisco. Jossey Bass.

8. Cameron BL, Mitchell AM (1993) Reflective peer journals. Developing authentic nurses. Journal of Advanced Nursing 18: 290-297.

9. Williams RM, Wessel J, Gemus M, Foster-Seargeant E (2002) Journal writing to promote reflection in physical therapy students during clinical placements. Physiotherapy - Theory and Practice 18: 5-15.

10. McCaugherty D (1991).Integrating theory and practice. Senior Nurse 12 : 36-39.

11. Mouniford $B$, Rogers $L$ (1996) Using individual and group reflection in and on assessment as a tool for effective learning. Journal of Advanced Nursing 24: $1127-1134$.

12. Mezirow $\mathrm{J}$ (1981) A critical theory of adult learning and education. Adult Education 32: 3-24.

13. Boud D, Keogh R, Walker D (1985) Reflection: Turning Experience into learning. London. Kogan Page.

14. Atkins S, Murphy K (1993) Reflection: review of the literature. Journal of Advanced Nursing 18: 1188-1192.

15. Leino-Kilpi $H$ (1990) Self-reflection in nurse teacher education. Journal of Advanced Nursing 15: 192-195.

16. Clarke B, James C, Kelly J (1994) Reflective Practice: broadening the scope. Paper presented to the Clinical Nurse Specialist Conference. Nottingham.

17. Jasper M (1999) Nurse's perceptions of the value of written reflection. Nurse Education Today19: 452-463.

18. James C (1995) Professional education - who learns what? Nurse Education Today 15: 161-163.

19. Callister LC (1993) The use of student journals in nursing education.Making meaning out of clinical experience. Journal of Nursing Education 41: 185186.

20. Button D, Davies S (1996) Experiences of encouraging studentcentredlearning within a weilness-orientated curriculum. Nurse Education Today. 16, pp. 407-412. 
Citation: Ueno M, Iwahara A, Yamada K, Morioka I (2017) Characteristics of Nurses in Japanese Hospitals Who Detect Errors of One-self and Others. Int J Nurs Clin Pract 4: 242. doi: https://doi.org/10.15344/2394-4978/2017/242

Page 3 of 3

21. Williams RM, Wilkins $S$ (1999) The use of reflective summary writing as a method of obtaining student feedback about entering physical therapy practice. Journal of Physical Therapy 13: 28-33.

22. Richardson G, Maltby H (1995) Reflection-on-practice: enhancing studentlearning. Journal of Advanced Nursing 22: 235-242.

23. Schön D (1991) The Reflective Practitioner, 2nd edn., San Francisco, Jossey Bass.

24. Polit D, Beck C (2010) Nursing Research: Appraising Evidence for Nursing Practice, 7th edn. Lippincott, Williams \& Wilkins, Philadelphia.

25. Krippendorff K (2004) Content Analysis: an Introduction to Its Methodology Sage, Thousand Oaks, California.

26. Colaizzi PE (1978) Psychological research as the phenomenological views it. In: R Valle, M. King (Eds.). Existential phenomenological alternatives for psychology: theories and methods, 183-210. London: Sage.

27. Graneheim UH, Lundman B (2004) Qualitative content analysis research concepts, procedures and measures to achieve trustworthiness. Nurse Education Today 24: 105-112.

28. Andrews M (2014) Using reflection to develop clinical expertise. British Journal of Nursing 8:1.

29. Jonsen E, Melender HL, Hilli $Y$ (2013) Finnish and Swedish nursing students experiences of their first clinical practice placement- a qualitative study. Nurse Education Today- Elsevier Ltd 33: 297-302.

30. Ross C, Mahal K, Chinnapen Y, Kolar M, Woodman K (2013) Evaluation of nursing students work experience through the use of reflective journals. Nursing Education Perspective 17: 21-27.

31. Ganzer CA, Zauderer C (2013) Structured Learning and self reflection strategies to decrease anxiety in the psychiatric mental health clinical nursing experience. Nursing Education Perspective 34: 244-247. 